\title{
Study of the NLRP3 inflammasome component genes and downstream cytokines in patients with type 2 diabetes mellitus with carotid atherosclerosis
}

\author{
Junli Lee ${ }^{1}$, Jing Wan², Linyun Lee', Changhua Peng ${ }^{1}$, Hailong Xie ${ }^{3}$ and Chengbin Lee ${ }^{1 *}$
}

\begin{abstract}
Background: A role for the NLRP3 inflammasome has been reported in various diseases, such as diabetes mellitus, atherosclerosis (AS), nephropathy, rheumatism, and others, although limited information is available concerning the role of the NLRP3 inflammasome, interleukin-1 $\beta$ (IL-1 $\beta$ ) and interleukin-18 (IL-18) in patients with type 2 diabetes mellitus (T2DM) and carotid atherosclerosis (CAS). Therefore, this cross-sectional study investigated these inflammatory components in patients with T2DM complicated with carotid atherosclerosis (T2DM + CAS).
\end{abstract}

Methods: A total of 107 inpatients or outpatients were included,including 81 T2DM + CAS patients and 26 T2DM patients. Patients with T2DM or T2DM + CAS were recruited to compare the expression levels of NLRP3 pathway genes (NLRP3, ASC and caspase-1 mRNA) and the serum IL-1 $\beta$ and IL-18 concentrations. In the T2DM + CAS group, patients with thickened intima media thickness (IMT) and those with plaques were compared, and the correlation of the 5 variables with Crouse scores were analyzed.

Results: The expression of NLRP3 pathway genes except caspase-1 was significantly higher in patients with T2DM and CAS compared to T2DM patients. Serum IL-1 $\beta$ and IL-18 concentrations shows no difference between the T2DM + CAS and T2DM group. In the T2DM + CAS group, the expression levels of the three inflammasome genes and IL-18 were increased in patients with thickened IMT compared to those with the plaque. All of the above factors negatively correlated with Crouse scores.

Conclusion: NLRP3 inflammasome pathway activity is significantly increased in patients with AS and T2DM at the early stage of plaque formation.

Keywords: NLRP3, Cytokines,type 2 diabetes mellitus,carotid atherosclerosis

\section{Background}

Diabetes mellitus is the second-leading cause of death among contemporary diseases. Vascular lesions, a complication of diabetes mellitus leading to high mortality, occur as a result of atherosclerosis (AS). AS and type 2 diabetes mellitus (T2DM) are metabolic diseases and share similar pathophysiological mechanisms, including NLRP3 (nucleotide-binding domain, leucine-rich-containing family, pyrin domain-containing-3) inflammasome activation,

\footnotetext{
*Correspondence: sh8498247@outlook.com

'Department of Clinical Laboratory, The second clinical medical college of yangtze university, Ren Min Road 1\#, Jingzhou, Hubei 434020, China

Full list of author information is available at the end of the article
}

which has been highlighted in recent studies [1, 2]. The NLRP3 inflammasome is the most well-studied inflammasome identified thus far; this cytosolic protein complex includes NLRP3, ASC (apoptosis-associated speck-like protein containing a CARD) and caspase-1 [3]. NLRP3 serves as the sensor of inflammasome activation, which can be triggered via cholesterol crystals, uric acid, microorganisms, and a variety of other ligands $[4,5]$. Following recognition of the corresponding ligand by NLRP3, the adaptor protein ASC is clustered to recruit caspase- 1 , which can cleave pro-IL- $1 \beta$ and pro-IL-18 to mature forms that participate in the innate immune response $[6,7]$. 
The pathological mechanisms for NLRP3 inflammasome activation and downstream cytokine production in T2DM have been elucidated. Indeed, inflammatory cytokines are crucial pathophysiological determinants of T2DM, as activated IL-1 $\beta$ and IL-18 can cause islet $\beta$ cell injury/death and dysfunction by inducing inflammationand immune cell infiltration. Insulin resistance or suppression of sensitivity then occurs, which leads to T2DM [8-10]. Emerging evidence suggests that newly diagnosed T2DM patients show significantly upregulated protein expression of NLRP3, ASC, caspase- 1 , IL- $1 \beta$ and IL-18 among monocyte-derived macrophages [11]. Furthermore, inhibition of caspase- 1 and IL- $1 \beta$ receptors can augment insulin sensitivity and ameliorate the secretory function of $\beta$ cells [12].

The relationship between AS and NLRP3 inflammasome activation and downstream cytokine production is ambiguous. IL- $1 \beta$ and IL-18 are two multifunctional cytokines involved in chronic inflammation that induce an intense inflammatory response, which is important in the pathogenesis and progression of AS [13]. Recent studies have demonstrated that atherogenesis can be initiated through the NLRP3 inflammasome pathway triggered by endogenous molecules, such as crystalline cholesterol [14]. Menu P et al. confirmed that the absence of NLRP3, ASC and capase-1, the core constituents of the NLRP3 inflammasome, did not affect AS progression in an apolipoprotein $\mathrm{E}$ (ApoE)-deficient mouse model [15]. Duewell P and coworkers [16] found contrasting results using a low-density lipoprotein receptor (LDLR)-deficient mouse model transplanted with NLRP3-, ASC-, or IL-1 $\beta$-deficient cells.

Because little is known about the NLRP3 inflammasome, IL-1 $\beta$ and IL-18 in patients with T2DM and AS, here we performed a cross-sectional study investigating these inflammatory components in patients with T2DM complicated with carotid atherosclerosis (CAS).

\section{Methods}

Research objects

In this cross-sectional study, a total of 107 inpatients or outpatients at the Jingzhou Affiliated Hospital of Huazhong Technology University were enrolled, including 81 T2DM + CAS patients (37 cases with increased intima media thickness (IMT) and 44 cases with plaque) and 26 T2DM patients. T2DM was diagnosed according to the American Diabetes Association (ADA) guidelines, defined as either (1) a fasting plasma glucose level of $\geq 126 \mathrm{mg} / \mathrm{dL}$, (2) a 2 -h plasma glucose level of $\geq 200 \mathrm{mg} /$ $\mathrm{dL}$ after a 75-g oral glucose tolerance test, or (3) a glycated hemoglobin level of $\geq 6.5 \%$. T2DM was confirmed by a result above the diagnostic threshold in two out of the three above-mentioned tests. Patients who were receiving antidiabetic medications (oral hypoglycemia agents and/or insulin) were deemed to have T2DM. All enrolled individuals showed no evidence of recent acute or chronic infectious disease, patients who have CVD including cerebral infarction, myocardial infarction (MI), angina, heart failure were also excluded. All examinations were permitted by participants and approved by the Ethics Committee of Jingzhou Central Hospital, Affiliated Tongji Medical College, Huazhong University of Science and Technology. Written consent was obtained from all participants according to the Declaration of Helsinki.

\section{Measurement of carotid plaque size and IMT}

The bilateral common carotid artery, carotid bifurcation, and internal and external carotid artery of participants were scanned using duplex ultrasonography with a 10$\mathrm{MHz}$ transducer (ie33, Ultrasound Imaging Systems, Holland). Plaque thickness was recorded and scored using the Crouse method [17]. If no plaque was found, the IMT at one site away from sinus in the common carotid artery was detected. Participants with an IMT > $1.5 \mathrm{~mm}$ were enrolled in the plaque group, whereas those with an IMT $\geq 1.0 \mathrm{~mm}$ and $\leq 1.5 \mathrm{~mm}$ were enrolled in the IMT thickened group.

\section{Measurement of serum IL-1ßand other factors}

Serum IL-1 $\beta$ and IL-18 concentrations were measured using commercially available enzyme-linked immunosorbent assay (ELISA) kits (TSZ Biotech, USA). Prior to sample detection, a standard curve was established with a correlation coefficient of 0.998 . The height, weight, blood pressure, peripheral blood leukocyte amount, mononuclear cell count, fasting blood glucose (FBG), serum triglyceride (TG), total cholesterol (TC), highdensity lipoprotein (HDL) and low-density lipoprotein (LDL) were also measured.

\section{Measurement of NLRP3 pathway genes}

1, RNA isolation and reverse transcription in: Fresh peripheral blood was obtained and centrifuged and then stratified using a Ficoll-Paque Plus density gradient $(20,130,613$, Solarbio Science, Beijing) according to the manufacturer's protocol. Peripheral blood monocytes cells (PBMCs) were acquired, and total RNA was isolated using TRIzol Reagent (14,105, Life Technologies, America). RNA was reverse transcribed to cDNA usingPromega MMLV reverse transcriptase (00021405, Gold Star, Beijing) according to the manufacturer's protocol. 2, Real-time fluorescence quantitative PCR: cDNA was amplified by real-time PCR with gene-specific primers (from Life Technologies). The constituents of the realtime PCR were added according to the manufacturer's protocol. The reaction conditions were as follows: $95^{\circ} \mathrm{C}$ for $10 \mathrm{~min} ; 10$ amplification cycles of $95{ }^{\circ} \mathrm{C}$ for $30 \mathrm{~s}, 56^{\circ} \mathrm{C}$ 
for $30 \mathrm{~s}$, and $62{ }^{\circ} \mathrm{C}$ for $45 \mathrm{~s}$; and then 30 amplification cycles of $95{ }^{\circ} \mathrm{C}$ for $15 \mathrm{~s}, 56{ }^{\circ} \mathrm{C}$ for $15 \mathrm{~s}$, and $62{ }^{\circ} \mathrm{C}$ for $45 \mathrm{~s}$. The PCR amplification products were verified by electrophoresis on $1.5 \%$ agarose gel and stained with ethidium bromide.

mRNA expression levels are described as $\Delta \Delta$ Ct (cycle threshold) values relative to the controls. Duplicate samples were subjected to RT-PCR, and the mean was used for analysis. The primers used for each gene were designed with Primer Express v2.0 (v. 0.4.0) andarelisted in Table 1.

\section{Statistics}

All data were analyzed with SPSS 13.0. Data with normal distribution are presented as mean \pm standard deviation and those with skewed distribution are presented as med$\operatorname{ian}\left(\mathrm{P}_{25} \sim \mathrm{P}_{75}\right)$. Fold change $(2-\Delta \Delta \mathrm{Ct})$ in mRNA expression were calculated relative to control subjects. Student's t test or Mann-Whitney $U$ test were used for comparison on continuous variables between two groups, The frequency data between two groups were compared by chi-squared test. All statistic test were two-tailed, A $p$ value $<0.05$ was considered statistically significant.

\section{Results}

\section{Basic characteristics of subjects}

Table 2 shows the demographic information for the T2DM and T2DM + CAS groups. No significant differences were observed regarding gender, drinking, smoking, FBG,TG, HDL, APOA between the two groups $(p>0.05)$. The ages of T2DM + CAS groups were higher than T2DM group $(p<0.05)$; however, there is no report indicating that age influences the expression of NLRP3 pathway genes and secretion of IL-1 $\beta$ and IL-18. The percentages of hypertension was also higher than T2DM group $(p<0.05)$, which is not surprising [18]. CHOL、LDL were higher in T2DM + CAS group than T2DM group $(p<0.05)$. Table 3 shows demographic information for the T2DM + AS patients with plaque or not. No significant differences were observed in the sex ratio, drinking, smoking, hypertension incidence or FBG between the IMT thicken and plaque group $(p>0.05)$.

Partial data are expressed as mean \pm standard deviation. "a" represent the $p$ value $<0.05$ compared with control; "b" represent the $p$ value $<0.05$ compared with $\mathrm{T} 2 \mathrm{DM}+\mathrm{CAS}$. Y/N, yes/no; BMI, body mass index; $\mathrm{T} 2 \mathrm{DM}+\mathrm{CAS}$, type 2 diabetes mellitus complicated with carotid atherosclerosis; T2DM, type 2 diabetes mellitus; CAS, carotid atherosclerosis; FBG, fasting blood glucose; TG, triglyceride; TC, total cholesterol; HDL, highdensity lipoprotein; LDL, low-density lipoprotein.

\section{Comparison of NLRP3 inflammasome component mRNA expression and IL-1 $\beta$ and IL-18 production}

We used the $2^{-\triangle \Delta \mathrm{Ct}}(\mathrm{Ct}$, cycle threshold) method to assess changes in mRNA expression. Table 4 denotes the mRNA expression levels of NLRP3 inflammasome component genes (NLRP3, ASC, and capase-1) in the T2DM and T2DM + CAS groups. The expression levels of NLRP3 and ASC mRNA were increased significantly in T2DM + CAS group compared with T2DM group $(p<0.05)$. However, no difference was observed in caspase-1, serum IL-1 $\beta$ and IL-18 concentrations in T2DM and T2DM + CAS group $(p>0.05)$.

Data are expressed as mean \pm standard deviation. "a" represent the $p$ value $<0.05$ compared with control; "b" represent the $p$ value $<0.05$ compared with T2DM + CAS. IL-1 $\beta$, interleukin-1 $\beta$; IL-18, interleukin-18. When divided T2DM + CAS group into IMT thickened and plaque groups, as shown in Table 5, the expression levels of the three inflammasome genes and IL-18 were increased compared with the plaque group $(p<0.05)$. The IL-1 $\beta$ level shows no difference between the two groups.

\section{Correlation between NLRP3 inflammasome mRNA expression, downstream cytokinesons and the Crouse scores}

Forty-four participants had plaque in the T2DM + CAS group, and the mean Crouse score in this group was $4.90 \pm 3.01$. The mRNA expression levels of NLRP3 inflammasome pathway genes and serum IL-18 concentrations were negatively correlated with the Crouse scores; the correlation coefficients are shown in Fig. 1.

\section{Discussion}

Diabetes and AS are metabolic diseases with a high global incidence. Diverse reports have suggested that metabolic diseases are associated with chronic inflammation, in which NLRP3 inflammasome activation and IL-1 $\beta$ and IL-18 cytokine production have been implicated [19-21]. Thus, assessing mRNA expression of NLRP3 inflammasome genes in vivo in various diseases in humansis essential to fully clarify the mechanisms of

Table 1 Primers for NLRP3 inflammasome component genes

\begin{tabular}{llll}
\hline & forward primer & reverse primer & probe \\
\hline NLRP3 & TGCCCGTCTG GGTGAGA & CCGGTGCTCCTTGATGAGA & TGAGCCTCAACAAACGCTAC ACACGACT \\
ASC & CGCGAGGGTC ACAAACGT & TGCTCATCCGTCAGGACCTT & AGTGGCTGCTGGATGCTCTG TACGG \\
caspase-1 & AATTTCCGCAAGGTTCGAT T & ACTCTTTCAGTGGTGGGCATCT & TCATTTGAGCAGCCAGATGG TAGAGCG \\
$\beta$-actin & GCTGTCTGCCTTGGTAGTGG AT & GCATCGTCACCACCAAAGC & ATGGGTCAGGGATGTGCAAG GCA \\
\hline
\end{tabular}


Table 2 Characteristics of T2DM patients combined with CAS or not

\begin{tabular}{|c|c|c|c|}
\hline Variables & $\mathrm{T} 2 \mathrm{DM}, n=26$ & $\mathrm{~T} 2 \mathrm{DM}+\mathrm{CAS}, n=81$ & $P$ \\
\hline Female, n (\%) & $13(50.0)$ & $31(38.3)$ & 0.290 \\
\hline Drinking, n (\%) & $3(11.54)$ & $20(24.69)$ & 0.155 \\
\hline Smoking, n (\%) & $9(34.62)$ & $30(37.04)$ & 0.823 \\
\hline Hypertension, n (\%) & $3(11.54)$ & $43(53.09)$ & $<0.001$ \\
\hline Age(year), mean \pm sd. & $51.42 \pm 10.2$ & $59.12 \pm 12.19$ & 0.004 \\
\hline Leukocyte $\left(10^{9} / \mathrm{L}\right)$, mean \pm sd. & $5.49 \pm 1.08$ & $6.46 \pm 2.07$ & 0.046 \\
\hline Mononuclear $\left(10^{9} / \mathrm{L}\right)$, mean $\pm \mathrm{sd}$ & $2.88 \pm 0.77$ & $3.96 \pm 2.02$ & 0.014 \\
\hline $\mathrm{FBG}(\mathrm{mmol} / \mathrm{l})$, mean $\pm \mathrm{sd}$ & $11.71 \pm 3.96$ & $10.31 \pm 3.27$ & 0.095 \\
\hline $\mathrm{TG}(\mathrm{mmol} / \mathrm{l})$, mean $\pm \mathrm{sd}$ & $2.57 \pm 2.72$ & $2.26 \pm 1.68$ & 0.681 \\
\hline $\mathrm{CHOL}(\mathrm{mmol} / \mathrm{l})$, mean $\pm \mathrm{sd}$. & $4.54 \pm 1.07$ & $5.03 \pm 1.28$ & 0.043 \\
\hline $\mathrm{HDL}(\mathrm{mmol} / \mathrm{l})$, mean $\pm \mathrm{sd}$ & $1.01 \pm 0.23$ & $1.06 \pm 0.24$ & 0.487 \\
\hline LDL(mmol/l), mean $\pm \mathrm{sd}$ & $2.56 \pm 0.76$ & $3.03 \pm 1.02$ & 0.014 \\
\hline $\mathrm{APOA}(\mathrm{g} / \mathrm{L})$, mean $\pm \mathrm{sd}$. & $1.35 \pm 0.2$ & $1.31 \pm 0.22$ & 0.468 \\
\hline $\mathrm{APOB}(\mathrm{g} / \mathrm{L})$, mean $\pm \mathrm{sd}$.) & $0.88 \pm 0.24$ & $1.03 \pm 0.29$ & 0.022 \\
\hline $\mathrm{LPa}(\mathrm{mg} / \mathrm{L})$, mean $\pm \mathrm{sd}$ & $100.19 \pm 103.77$ & $148.89 \pm 176.1$ & 0.085 \\
\hline
\end{tabular}

pathogenesis and determine targeted therapy for inflammatory diseases.

Recent studies have shown that NLRP3, ASC and caspase-1 expression and IL-1 $\beta$ and IL-18 secretion are increased under high-glucose conditions in vivo and in vitro $[11,22,23]$. Additionally, upregulated expression of inflammasome components and downstream cytokines was demonstrated in atherosclerotic patients and animal models $[24,25]$. In our study, results in Table 4 shows that NLRP3 mRNA and ASC mRNA were increased significantly in T2DM patients and CAS patients compared with T2DM patients $(p<0.05)$ corroborate these previous findings, excluding the caspase-1 expression levels which possibly due to negative regulation of the NLRP3 pathway [7, 26, 27]. In addition, serum IL-18 concentrations in the T2DM group and T2DM + CAS group shows no difference $(p>0.05)$. The many influencing factors of IL-18 levels in blood make it difficult to interpret these results, and further studies are needed to investigate additional mechanisms.

There are few reports on the NLRP3 inflammasome in patients with diabetes with CAS. LI Y et al. [28] suggested merely that NLRP3 inflammasome markers were increased in diabetic pigs with atherosclerotic lesions

Table 3 Characteristics of T2DM + CAS patients with plaque or not

\begin{tabular}{|c|c|c|c|}
\hline Variables & IMT thicken, $n=32$ & Plaque, $n=49$ & $P$ \\
\hline Female, n (\%) & $13(40.63)$ & $18(36.73)$ & 0.725 \\
\hline Drinking, n (\%) & $10(31.25)$ & $10(20.41)$ & 0.269 \\
\hline Smoking, n (\%) & $12(37.50)$ & $18(36.73)$ & 0.944 \\
\hline Hypertension, n (\%) & $13(40.63)$ & $30(61.22)$ & 0.069 \\
\hline Age(year), mean \pm sd. & $52.34 \pm 11.01$ & $63.55 \pm 10.9$ & $<0.001$ \\
\hline Leukocyte $\left(10^{9} / \mathrm{L}\right)$, mean \pm sd. & $6.6 \pm 2.58$ & $6.36 \pm 1.65$ & 0.865 \\
\hline Mononuclear $\left(10^{9} / \mathrm{L}\right)$, mean $\pm \mathrm{sd}$ & $4.11 \pm 2.48$ & $3.86 \pm 1.65$ & 0.848 \\
\hline $\mathrm{FBG}(\mathrm{mmol} / \mathrm{l})$, mean $\pm \mathrm{sd}$ & $10.56 \pm 2.70$ & $10.15 \pm 3.61$ & 0.223 \\
\hline $\mathrm{TG}(\mathrm{mmol} / \mathrm{l})$, mean $\pm \mathrm{sd}$ & $2.53 \pm 2.13$ & $2.09 \pm 1.30$ & 0.823 \\
\hline $\mathrm{CHOL}(\mathrm{mmol} / \mathrm{l})$, mean $\pm \mathrm{sd}$. & $5.04 \pm 1.28$ & $5.02 \pm 1.30$ & 0.924 \\
\hline $\mathrm{HDL}(\mathrm{mmol} / \mathrm{l})$, mean $\pm \mathrm{sd}$ & $1.10 \pm 0.24$ & $1.04 \pm 0.25$ & 0.301 \\
\hline $\mathrm{LDL}(\mathrm{mmol} / \mathrm{l})$, mean $\pm \mathrm{sd}$ & $3.07 \pm 1.11$ & $3.01 \pm 0.98$ & 0.932 \\
\hline $\mathrm{APOA}(\mathrm{g} / \mathrm{L})$, mean $\pm \mathrm{sd}$ & $1.35 \pm 0.24$ & $1.29 \pm 0.21$ & 0.305 \\
\hline $\mathrm{APOB}(\mathrm{g} / \mathrm{L})$, mean $\pm \mathrm{sd}$ & $1.05 \pm 0.30$ & $1.01 \pm 0.29$ & 0.621 \\
\hline $\mathrm{LPA}(\mathrm{mg} / \mathrm{L})$, mean $\pm \mathrm{sd}$ & $152.07 \pm 160.76$ & $146.83 \pm 187.14$ & 0.770 \\
\hline
\end{tabular}


Table 4 NLRP3, ASC, Caspase-1, IL-1 and IL-18 level in T2DM patients combined with CAS or not

\begin{tabular}{llll}
\hline Variables & T2DM, $n=26$ & T2DM + AS, $n=81$ & $P$ \\
\hline NLRP3 mRNA, mean \pm sd. & $1.74 \pm 0.81$ & $3.38 \pm 1.74$ & $<0.001$ \\
ASC mRNA, mean \pm sd. & $2.07 \pm 0.92$ & $2.48 \pm 0.61$ & 0.033 \\
Caspase-1 mRNA, mean \pm sd. & $2.86 \pm 2.17$ & $3.64 \pm 1.80$ & 0.065 \\
IL-1 $\beta(\mathrm{pg} / \mathrm{ml})$, mean \pm sd. & $56.06 \pm 36.97$ & $54.87 \pm 26.81$ & 0.561 \\
$\mathrm{IL}-18(\mathrm{pg} / \mathrm{ml})$, mean $\pm \mathrm{sd}$. & $158.29 \pm 88.96$ & $149.2 \pm 67.96$ & 0.996 \\
\hline
\end{tabular}

compared with control pigs. Here, we investigated the mRNA expression levels of NLRP3 and ASC from T2DM + CAS patients were significantly higher than purely diabetic patients $(p<0.05)$. AS we know, NLRP3 can detect endogenous danger signals, such as high glucose, fatty acid, uric acid, cholesterol crystals, and bacteria, and cholesterol crystals are considered the primary activator of NLRP3 during atherosclerotic plaque formation $[2,13,29,30]$. IL-1 $\beta$ and IL-18 are downstream cytokines of the NLRP3 inflammasome, and their serum concentrations are predictors of AS and T2DM [20]. Thus, under conditions of high glucose in the presence of cholesterol crystals, the inflammatory immune response is greater. So, the NLRP3 inflammasome pathway can be synergistically activated by hyperglycemia and AS, with consequently increased mRNA expression of NLRP3, ASC and caspase-1.

Then T2DM + CAS patients in our study were divided into IMT thickened and plaque groups. The measurement of IMT or plaque by ultrasonography is essential to detect prevalent cardiovascular diseases [31]. Increased IMT is considered an early event in the formation of plaques or AS. The mRNA expression levels of NLRP3 inflammasome component genes and the serum IL-18 levels in the IMT thickened group were significantly increased compared to those in the plaque group $(p<0.05)$, demonstrating that the inflammatory response mediated by the NLRP3 inflammasome was more active at the early stage of plaque formation. At this stage, vascular lesions cause macrophage infiltration, foam cell formation and lipid deposits, followed by lipid accumulation and increased IMT and persistent NLRP3 inflammasome activation. With plaque progression, the fibrous cap forms, and mixtures containing cholesterol clefts are produced. Thus, it is possible that the response of NLRP3 inflammasome diminished due to the consumption of these cholesterol substances at the mid-advanced stage of plaque formation [27, 32, 33]. Many immune cells can be detected in subendothelial areas in the early stage of AS plaque formation [34], and IL- $1 \beta$ and IL-18 activation is considered the core element of AS formation [35]. As shown in Table 5, NLRP3, ASC, caspase-1 and serum IL-18 levels in the IMT thickened group were higher than those in the plaque group, which also shows that the downstream cytokines of the NLRP3 inflammasome were more active at the early stage of plaque formation.

The present study also explored the relationship between Crouse plaque scores and the mRNA expression levels of NLRP3, ASC, caspase-1 and serum IL-1 $\beta$ and IL18 concentrations in the plaque group. The Crouse score is used to evaluate the AS plaque burden and is associated with CAS severity [36]. As shown in Fig. 1, the Crouse score was negatively correlated with these factors. These data further confirm that the NLRP3 inflammasome pathway is more active at the early stage of plaque formation in T2DM + CAS patients.

From the investigation, we found that the degree of activation of the NLRP3 inflammasome pathway was higher when AS coincided with T2DM, with greater activity observed at the early stage of plaque formation in this study. However, the combination of T2DM and CAS is a complex pathological phenomenon that requires further research, such as gene knockout experiments or histopathology, to reveal potential mechanisms responsible for disease development and progression [32].

\section{Conclusion}

In this study, we uncover the inflammasome pathway of NLRP3 is remarkably increased in patients with AS and T2DM at the early stage of plaque formation. The current study has some limitations. First, our study is a cross-

Table 5 NLRP3, ASC, Caspase-1, IL-1 and IL-18 level in T2DM + AS patients with plaque or not

\begin{tabular}{llll}
\hline Variables & IMT thicken, $n=32$ & Plaque, $n=49$ & $P$ \\
\hline NLRP3 mRNA, mean \pm sd. & $3.84 \pm 1.51$ & $2.95 \pm 1.20$ & 0.004 \\
ASC mRNA, mean \pm sd. & $2.76 \pm 0.51$ & $2.21 \pm 0.39$ & $<0.001$ \\
Caspase-1 mRNA, mean \pm sd. & $4.39 \pm 1.63$ & $2.94 \pm 1.74$ & $<0.001$ \\
IL-1 $\beta(\mathrm{pg} / \mathrm{ml})$, mean \pm sd. & $60.48 \pm 35.01$ & $51.51 \pm 20.19$ & 0.682 \\
$\mathrm{IL}-18(\mathrm{pg} / \mathrm{ml})$, mean $\pm \mathrm{sd}$. & $186.57 \pm 73.47$ & $126.77 \pm 53.88$ & 0.003 \\
\hline
\end{tabular}

Partial data are expressed as mean \pm standard deviation 

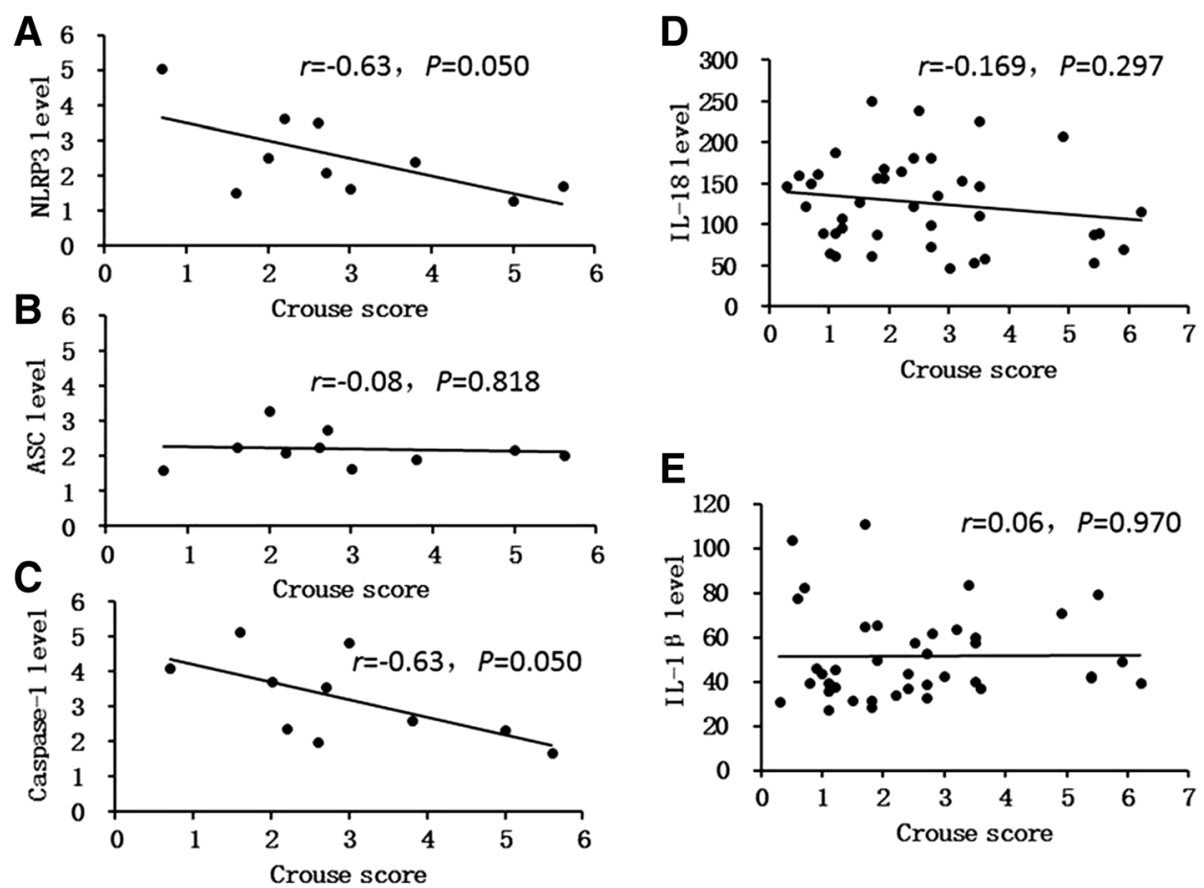

Fig. 1 Correlation between NLRP3 inflammasome component genes expression, downstream cytokinesons and the Crouse scores. a, b and $\mathbf{c}$ NLRP3 mRNA、ASC mRNA、Caspase-1 mRNA expression in PBMCs of T2DM + CAS patients show negative correlation to Crouse scores separately. $\mathbf{d}$ and e Serum IL-18 concentrations were negatively correlated with the Crouse scores evidently, but Serum IL-1 $\beta$ concentrations were not

sectional study, the number of subjects and selected diseases were limited. The second limitation is that only part of the experiment index and diabetic patients with carotid artery were observed. However, our findings of NLRP3 inflammasome pathway activity is significantly increased in patients with AS and T2DM at the early stage of plaque formation provides a potential therapeutic strategy to treat these patients. In the future studies, the large prospective study, demonstration of related gene knockout in animal model and the study of anti-inflammatory cytokines, warrant further investigation.

\footnotetext{
Abbreviations

ADA: American Diabetes Association; ApoE: AS progression in an apolipoprotein E; AS: Atherosclerosis; CAS: Carotid atherosclerosis;

FBG: Fasting blood glucose; HDL: High-density lipoprotein; IL-18: Interleukin18; IL-1 $\beta$ : Interleukin-1 $\beta$; IMT: Intima media thickness; LDL: Low-density lipoprotein; LDLR: Low-density lipoprotein receptor; MI: Myocardial infarction; NLRP3: Nucleotide-binding domain, leucine-rich-containing family, pyrin domain-containing-3; T2DM + CAS: T2DM complicated with carotid atherosclerosis; T2DM: Type 2 diabetes mellitus; TC: Total cholesterol; TG: Serum triglyceride
}

\section{Acknowledgements}

We are grateful to all study participants and thank Mr. Changfu Wang for establishing the experimental protocol and Mr. Bin Mei for discussions.
Availability of data and materials

The datasets supporting the conclusions of this article are included within the article.

\section{Authors' contributions}

$\mathrm{CL}$ contributed to the study design, $\mathrm{JL}$ and JW prepared the manuscript, $\mathrm{LL}$ collected the data, CP perform the data analysis, HX polished the manuscript, all the authors made the final approval. All authors read and approved the final manuscript.

\section{Ethics approval and consent to participate}

The study protocol was approved by the Ethic Committee of the The Second Clinical Medical College of Yangtze University and conducted in accordance with Helsinki's Declaration. All the patients gave their written information consent.

\section{Consent for publication \\ Not applicable.}

\section{Competing interests}

The authors declare that they have no competing interests.

\section{Publisher's Note}

Springer Nature remains neutral with regard to jurisdictional claims in published maps and institutional affiliations.

\section{Author details}

'Department of Clinical Laboratory, The second clinical medical college of yangtze university, Ren Min Road 1\#, Jingzhou, Hubei 434020, China. ${ }^{2}$ Department of Endocrinology, The second clinical medical college of yangtze university, Jingzhou, China. ${ }^{3}$ Department of Clinical Medicine, Graduate School of Yangtze University, Jingzhou, China. 
Received: 12 September 2017 Accepted: 19 October 2017

Published online: 18 November 2017

\section{References}

1. De Nardo D, Latz E. NLRP3 inflammasomes link inflammation and metabolic disease. Trends Immunol. 2011;32(8):373-9.

2. Ordovas-Montanes JM, Ordovas JM. Cholesterol, Inflammasomes, and Atherogenesis. Curr Cardiovasc Risk Rep. 2012;6(1):45-52.

3. Lee MS. Role of innate immunity in diabetes and metabolism: recent progress in the study of inflammasomes. Immune Netw. 2011;11(2):95-9.

4. Grant RW, Dixit VD. Mechanisms of disease: inflammasome activation and the development of type 2 diabetes. Front Immuno. 2013;4:50.

5. Sutterwala FS, Haasken S, Cassel SL. Mechanism of NLRP3 inflammasome activation. Ann N Y Acad Sci. 2014;1319(1):82-95.

6. Jha S, Srivastava SY, Brickey WJ, et al. The Inflammasome sensor, NLRP3, regulates CNS inflammation and Demyelination via Caspase-1 and Interleukin-18. J Neurosci. 2010;30(47):15811-20.

7. Leemans JC, Cassel SL, Sutterwala FS. Sensing damage by the NLRP3 inflammasome. Immunol Rev. 2011;243(1):152-62.

8. K M, Dharmadhikari G, Schumann DM. Interleukin-1 beta targeted therapy for type 2 diabetes. Expert Opin Biol Ther. 2011;9(9):1177-88.

9. Stienstra $R$, Joosten LA, Koenen $T$, et al. The Inflammasome-mediated Caspase-1 activation controls Adipocyte differentiation and insulin sensitivity. Cell Metab. 2010;12(6):593-605.

10. Dixit VD. Nlrp3 inflammasome activation in type 2 diabetes: is it clinically relevant? Diabetes. 2013;62(1):22-4.

11. Lee HM, Kim JJ, Kim HJ, et al. Upregulated NLRP3 inflammasome activation in patients with type 2 diabetes. Diabetes. 2013;62(1):194-204.

12. Koenen TB, Stienstra $R$, van Tits $L$, et al. Hyperglycemia activates caspaseand TXNIP mediated IL-1 beta transcription in human adipose tissue. Diabetes. 2011;60(2):517-24.

13. Samstad EO, Niyonzima N, Nymo S, et al. Cholesterol crystals induce complement-dependent inflammasome activation and cytokine release. J Immunol. 2014;192(6):2837-45.

14. Li X, Zhang Y, Xia M, et al. Activation of Nlrp3 inflammasomes enhances macrophage lipid-deposition and migration: implication of a novel role of inflammasome in atherogenesis. PLoS One. 2014;9(1):e87552.

15. Menu P, Pellegrin M, Aubert JF, et al. Atherosclerosis in ApoE-deficient mice progresses independently of the NLRP3 inflammasome. Cell Death Dis. 2011;2:e137.

16. Duewell $\mathrm{P}$, Kono $\mathrm{H}$, Rayner $\mathrm{KJ}$, et al. NLRP3 inflammasomes are required for atherogenesis and activated by cholesterol crystals. Nature. 2010;464(7293): 1357-61.

17. Crouse JR, Harapold GH, Kahl FR, et al. Evaluation of a scoring system for extracanial cartid atherosclerosis extent with B-mode ultrasound. Stroke. 1986;17(2):270-5.

18. Al-Shukaili A, AL-Ghafri S, Al-Marhoobi S, et al. Analysis of inflammatory mediators in type 2 diabetes patients. Int J Endocrinol. 2013;2013:976810.

19. Fullerton MD, Steinberg GR, Schertzer JD. Immunometabolism of AMPK in insulin resistance and atherosclerosis. Mol Cell Endocrinol. 2013;366(2):224-34.

20. Nakamura A, Shikata K, Hiramatsu M, et al. Serum interleukin-18 levels are associated with nephropathy and atherosclerosis in Japanese patients with type 2 diabetes. Diabetes Care. 2005;28(12):2890-5

21. Masters SL, Dunne A, Subramanian SL, et al. Activation of the NLRP3 inflammasome by islet amyloid polypeptide provides a mechanism for enhanced IL-1ß in type 2 diabetes. Nat Immunol. 2010;11(10):897-904.

22. Huang $X$, Yang $X, N i$ J, et al. Hyperglucose contributes to Periodontitis: involvement of the NLRP3 pathway by engaging in innate immunity of oral gingival epithelium. J Periodontol. 2014;17:1-19.

23. Chen K, Zhang J, Zhang W, et al. A7IP-P2X4 signaling mediatesNLRP3 inflammasome activation: a novel pathway of diabetic nephropathy. Int J Biochem Cell Biol. 2013;45(5):932-43.

24. Zheng F, Xing S, Gong Z, et al. NLRP3 inflammasomes show high expression in aorta of patients with atherosclerosis. Heart Lung Circ. 2013:22(9):746-50

25. Wang L, Qu P, Zhao J, et al. NLRP3 and downstream cytokine expression elevated in the monocytes of patients with coronary artery disease. Arch Med Sci. 2014;10(4):791-800.

26. Dagenais M, Skeldon A, Saleh M. The inflammasome: in memory of Dr. Jurg Tschopp. Cell Death Differ. 2012;19(1):5-12.
27. Yang C-S, Kim J-J, Kim TS, et al. Small heterodimer partner interacts with NLRP3 and negatively regulates activation of the NLRP3 inflammasome. Nat Commun. 2015;6:6115

28. $\mathrm{LI} Y, X u \mathrm{~S}$, Jiang $B$, et al. Activation of sterol regulatory element binding protein and NLRP3 inflammasome in atherosclerotic lesion development in diabetic pigs. PLoS One. 2013;8(6):e67532.

29. Grebe A, Latz E. Cholesterol crystals and inflammation. Curr Rheumatol Rep. 2013;15(3):313.

30. Kelly MS, Denise MM. Bacterial recognition pathways that lead to inflammasome activation. Immunol Rev. 2015;265(1):112-29.

31. Polak JF1, Pencina MJ, Meisner A, et al. Associations of carotid artery intimamedia thickness (IMT) with risk factors and prevalent cardiovascular disease: comparison of mean common carotid artery IMT with maximum internal carotid artery IMT. J Ultrasound Med. 2010;29(12):1759-68.

32. Zheng F, Xing S, Gong Z, et al. Silence of NLRP3 suppresses atherosclerosis and stabilizes plaques in apolipoprotein E-deficient mice. Mediat Inflamm. 2014;2014:507208.

33. Keymel S, Heinen Y, Balzer J, et al. Characterization of macro- and microvascular function and structure in patients with type 2 diabetes mellitus. Am J Cardiovasc Dis. 2011;1(1):68-75.

34. Rajamäki K, Lappalainen J, Oörni K, et al. Cholesterol crystals activate the NLRP3 inflammasome in human macrophages: a novel link between cholesterol metabolism and inflammation. PLoS One. 2010;5(7):e11765.

35. Lu X, Kakkar V. Inflammasome and atherogenesis. Curr Pharm Des. 2014;20(1):108-24.

36. Peters SA, Dogan S, Meijer $R$, et al. The use of plaque score measurements to assess changes in atherosclerotic plaque burden induced by lipidlowering therapy over time: the METEOR study. J Atheroscler Thromb. 2011:18(9):784-95.

\section{Submit your next manuscript to BioMed Central and we will help you at every step:}

- We accept pre-submission inquiries

- Our selector tool helps you to find the most relevant journal

- We provide round the clock customer support

- Convenient online submission

- Thorough peer review

- Inclusion in PubMed and all major indexing services

- Maximum visibility for your research

Submit your manuscript at www.biomedcentral.com/submit 